Alexis V. Pinilla Díaz

\title{
Dimensiones educativas de la televisión en contextos familiares de la localidad 12 de Bogotá
}

Resumen. En este artículo se realiza un acercamiento a las relaciones que se establecen entre televisión, familia y educación, en el contexto de los hogares de la localidad 12 (Barrios Unidos). Inicial-mente se puede afirmar que de acuerdo con las indagaciones hechas en la localidad, podemos identtficar, principalmente, tres funciones o usos de la televisión en el hogar: entretenimjento, información y educación. En cuanto a ésta última es posible encontrar dos dimensiones educativas de la televisión: como dispositivo pedagógico y como dispositivo político normativo, a las cuales se hará alusión en la segunda parte del artículo, después de presentar algunos antecedentes temáticos sobre las investigaciones en televisión y familia en diferentes países.

Palabras clave. Televisión, familia, educación, Bogotá.

Abstract. The purpose of this article is to discuss the relationship among television, family and education in the context of 12 District (Barrios Unidos, Bogotá, Colombia). First of all, we can state that according to our research in that District, three main functions or uses of home television can be identtfied: entertainment, information and education. With respect to the last one we can find two educational dimensions: as a pedagogical device and as a political one. Reference to these devices will be made on the second part of this article after presenting the results some previous research about television and family in dfferent countries.

Keywords. Television, family, education, Bogotá.

\section{Antecedentes de la investigación sobre televisión y familia}

En América Latina el tema de familia y televisión ha venido ocupando la atención de diversos investigadores desde los años 80 . Vale la pena destacar, entre otros, los trabajos del venezolano Leoncio Barrios, quien en su libro Familia y Televisión hace unas observaciones sobre las relaciones familia, televisión y educación. Con experiencias concretas de familias venezolanas, Barrios llega a la conclusión de que se ha operado en la sociedad moderna un desplazamiento de

\footnotetext{
${ }^{*}$ Profesor del Departamento de Ciencias Sociales, Universidad Pedagógica Nacional.

** Este artículo hace parte del informe final del proyecto de investigación La televisión en la familia y la familia en la televisión, cofinanciado por la Comisión Nacional de Televisión y la Fundación Universitaria Los Libertadores. Además del autor del artículo, el grupo estuvo integrado por los profesores Tomás Vásquez, Guillermo Cárdenas, Édgar Robayo y Alejandro Martínez, de la Fundación Universitaria Los Libertadores.
} 
algunas de las funciones educativas de la familia por parte de otras instituciones de educación informal, entre las cuales se destaca la televisión ${ }^{1}$.

En otras investigaciones se ha planteado el problema tomando como objeto de estudio la familia y el hogar. En esta perspectiva, Valerio Fuenzalida ${ }^{2}$ analizó la necesidad de que la familia asuma más conscientemente su papel de orientadora de las relaciones entre niños y adolescentes y la televisión ${ }^{3}$. Por su parte, el grupo CENECA, pionero en los estudios sobre la relación televisión y familia desde 1982, incluye en sus experiencias talleres a padres de familia, buscando la participación activa de los sujetos familiares en los procesos de recepción y lectura crítica de medios, en particular de la televisión ${ }^{4}$.

En México, el investigador Guillermo Orozco aborda la temática de familia y televisión, asumiendo la familia como escenario privilegiado de interacción con la televisión, o como comunidad de apropiación del mensaje televisivo. Este autor orienta su trabajo desde la perspectiva Medios-Familia-Escuela, concebidas como instituciones que no se pueden desagregar al examinar los procesos de recepción. Sus estudios tienen como objeto principal a niños y adolescentes. Uno de los conceptos que aporta Orozco es el de mediaciones múltiples, es decir, que en los procesos de recepción participan, de modo complejo, las mediaciones familiares, es-colares, religiosas y políticas, en la conformación de las representaciones que los sujetos receptores hacen de los mensajes.

Para el caso argentino, es importante destacar el trabajo de Jorge Huergo quien, apoyado en los aportes de las pedagogías críticas, en algunos elementos de la filosofía foucaultiana y en el concepto de mediaciones, ha venido reflexionando sobre las relaciones entre cultura escolar y cultura mediática y sus implicaciones en los procesos de socialización de jóvenes y niños. Para este autor, la cultura mediática, entendida como un escenario de transformación de prácticas, saberes y representaciones sociales, "opera también desde dentro de la cotidianidad, más allá de las situaciones específicas de 'recepción', 'audienciación' o del carácter de 'público', 'consumidores' o 'usuarios' que pueden asumir los sujetos, extendiéndose a todas las formas de la vida social"".

En Perú, los trabajos de Rosa María Alfaro y Sandro Macassi, publicados en el libro Seducidos por la Tele, analizan a la familia como actor principal en las iniciativas educativas que se adelantan sobre la televisión desde la escuela y algunos grupos de la sociedad civil. En términos generales, las investigaciones de

\footnotetext{
${ }_{1}^{1}$ Barrios, Leoncio. Familia y televisión, Caracas, Monte Ávila ditores, 1992.

${ }^{2}$ Fuenzalida, Valerio. Televisión, padres e hijos, Santiago de Chile, Ediciones Paulinas, 1984.

${ }^{3}$ Ibid., p 108.

${ }^{4}$ Charles, Mercedes y Orozco, Guillermo. Educación para la recepción. Lectura crítica de medios. México, Trillas, 1990.

5 Huergo, Jorge Alberto y Hernández, Maria Belén. CulturaEscolar Cultura mediática / Intersecciones, Bogotá, Universidad Pedagógica Nacional, 1999, p. 47.

${ }^{6}$ Alfaro, Rosa María y Macassi, Sandro. Seducidos por laTele. Huellas educativas de la televisión en padres y nulos, Lima, Clandria, 1995.
} 
estos autores propenden por la sensibilización de los padres de familia en torno al uso de la televisión en los procesos de socialización de los niños y jóvenes escolares en la ciudad de Lima. En este mismo país, Teresa Quiroz ${ }^{7}$ ha trabajado las implicaciones de la televisión, buscando definir el papel de la escuela y la televisión en la reconfiguración de los procesos de socialización.

Para el caso europeo podemos referenciar las investigaciones de David Morley ${ }^{8}$ quien, partiendo de los estudios culturales, analiza cómo los televidentes le dan sentido a los materiales que ven, pero también las relaciones sociales dentro de las cuales la recepción tiene lugar. Entre estas relaciones vale destacar las de género y las que se establecen entre lo público y lo privado. Para este autor la familia es la unidad social en la cual se produce la mayor parte del consumo temprano de medios, por lo cual ésta debe ocupar un lugar significativo en los estudios que relacionen televisión y cultura. Otro investigador del contextó europeo es Roger Silverstone, quien en su libro Televisión y vida cotidiana ${ }^{9}$ hace una fenomenología de la familia, la casa y el hogar, como espacios de vivencia cotidiana, en los cuales se construyen los sujetos sociales contemporáneos. En estos lugares la televisión cumple el papel de dinamizadora de las transformaciones de la vida cotidiana.

En el caso español, es de interés señalar un trabajo realizado conjuntamente por investigadores de la Universidad Complutense y la UNED ${ }^{10}$, en el cual se entiende a la televisión no sólo como un instrumento técnico, sino más bien como un objeto social que es construido por los sujetos y, por ende, da pie a distintas representaciones sobre el mismo. Basados en una estrategia cualitativa de investigación, los autores señalan que hay una notable distancia entre, por un lado, la facilidad con que circula el discurso de la fuerte influencia de la televisión sobre los niños y adolescentes y, en menor grado, entre padres, y, por otro lado, la vivencia concreta de la percepción de tal influencia. Teniendo en cuenta lo anterior, según los autores, la televisión funciona en la familia como un mecanismo de premios y castigos para los niños.

También en España, José Aguaded ${ }^{11}$ hace hincapié en el proceso por medio del cual las audiencias, en su función de telespectadores, se apropian de la televisión. Para este autor el reto del convivir con la televisión se centra en entender a la misma, convivir con ella y disfrutar de su esparcimiento. La

\footnotetext{
${ }^{7}$ Quiroz, María Teresa. Todas las voces. Comunicación y educación en el Perd, Lima. Universidad de Lima, 1993.

${ }^{8}$ Morley, David. Televisión, audiencias y estudios culturales, Buenos Aires, Amorrortu Editores, 1996.

${ }^{9}$ Silverstone, Roger. Televisión y vida cotidiana, Buenos Aires, Amorrortu. 1996.

${ }^{10}$ García, María Luisa; Callejo Gallego, Javier; Del Val Cid, Consuelo; Camarero Rioja, Luis A. y Arranz Lozano, Fátima. La influencia de la familia y los educadores en la percepción y asunción de Los mandatos sobre la televisión, Barcelona, Centro Nacional de Investigación y Documentación Educativo, Ministerio de Educación y Ciencia, 1994.

${ }^{11}$ Aguaded, José. Convivir con la televisión. Familia, educación y recepción televisiva, Buenos Aires, Paidós, 1999.
} 
televidencia es otro de los apartados que surgen de la reflexión y la investigación con tendencias hacia el análisis de los entornos mediacionales, las comunidades de apropiación y las comunidades de generación de sentidos. Finalmente propone, como reto para la educación, la competencia televisiva, en la que el elemento central lo constituye la lectura de la televisión en el universo de sentidos en que ésta se representa.

En el ámbito nacional, un trabajo en el cual se empezó a evidenciar la importancia del análisis en torno al tema familia y televisión fue el realizado por Jesús Martín-Barbero ${ }^{12}$, para quien la familia es la unidad básica de la audiencia televisiva; sustentando, además, cómo las relaciones familiares se encuentran atravesadas por las propuestas televisivas, las cuales son asumidas desde las mediaciones culturales de los sujetos. Retomando algunos elementos del trabajo de Martín-Barbero, Maritza López de la Roche ${ }^{13}$, ha centrado sus búsquedas en la relación de la infancia con los medios de comunicación. Su estudio - realizado entre 1996 y 1998 con el apoyo del Instituto Colombiano de Bienestar Familiar, el Ministerio de Comunicaciones y la Universidad del Valle- tuvo como objetivo identificar los imaginarios que los niños construyen sobre la familia, la ciudad, el país y el mundo. En esta perspectiva, la pregunta central de la investigación se orientaba a la forma en que las imágenes de los medios, principalmente de la televisión, intervienen en la reconstrucción de las representaciones que los niños hacen de la realidad.

Los principales temas tocados por el equipo coordinado por Maritza López giran en torno a estrategias de lecto-escritura de los medios, relaciones entre familia y televisión, imágenes de barrio y ciudad, el país que se representan los niños, imágenes de mundo que construyen los niños y las relaciones que se tejen entre medios de comunicación, infancia y maestros. En lo concerniente a la importancia del estudio sobre la familia y las relaciones entre ésta y la televisión, Maritza López anota que "el deterioro de los valores claves de la ética social en Colombia, y la grave situación de violencia cotidiana y política dentro de la cual convivimos, son dos de las razones para pensar en la familia como uno de los núcleos humanos al cual apelar con miras a buscar transformaciones que sentimos necesarias para la sociedad colombiana"14.

Por su parte, los estudios de Nora Segura se centraron en el consumo televisivo de las familias en la ciudad de Cali a finales de la década del 80 . Uno de los presupuestos teóricos de este análisis fue mirar a la televisión como un escenario en el cual el actor social construye la realidad cotidiana como marco de su acción en y sobre el mundo. En este sentido, para Segura, "la aprehensión selectiva de los contenidos televisivos opera sobre su forma particular de

\footnotetext{
${ }^{12}$ Martln-Barbero, Jesús. De los medios a las mediaciones. Comunicación, cultura y hegemonía, Barcelona, Gustavo Gui, 1987.

${ }^{13}$ López de la Roche, Maritza; Martín-Barbero, Jesús; Rueda, Amanda y Valencia, Stella. Los Niños como audiencias. Investigación sobre recepción de medios, Bogotá, Instituto Colombiano de Bienestar Familiar, Proyecto Comunicación para la infancia. 2000, p. 25.

14 Ibid., p. 107.
} 
comprensión del mundo, sobre el sentido de su vida cotidiana en un contexto social que se postula organizado, y participa de unas formas culturales que lo identifican como una colectividad [...] y con un imaginario compartido"'15.

Por su parte, los trabajos de Jorge Yarce se centraron en analizar los efectos que produce la televisión en los valores familiares. Así, desde una concepción de la comunicación que busca regular los comportamientos humanos, el autor sugiere estrategias pedagógicas para que los padres de familia orienten la audiencia televisiva de sus hijos. Basado en una mirada valorativa sobre lo bueno y lo malo, Yarce enuncia una serie de programas televisivos, de carácter nacional e internacional, calificando su impacto en la destrucción de los valores familiares y en las posibilidades de hacer frente a tales contenidos ${ }^{16}$.

Otros autores nacionales han hecho algunas referencias ocasionales a las relaciones familia y televisión, partiendo de la crítica a los medios de comunicación, particularmente a la televisión. Tal es el caso de Omar Rincón, para quien la televisión, entendida como agente socializador, penetra las instituciones de poder, tanto la familia como la escuela, y genera un valor instrumental como canahizador del tiempo libre en el hogar o como factor de enseñanza-aprendizaje en la escuela ${ }^{17}$. Rincón realiza un análisis de la televisión como institución social y como práctica cultural para intentar desentrañar la vieja relación poder-saber, campo en el cual se dejan varios interrogantes abiertos para futuros trabajos de investigación.

En el plano institucional, los estudios sobre el impacto de los medios en la familia se pueden reseñar a partir de la década de los 80 , cuando el gobierno colombiano estableció convenios con la UNICEF En este marco se desarrolló el Proyecto de Comunicación para la Infancia del Instituto Colombiano de Bienestar Familiar, iniciado en 1984, como una estrategia dirigida a través del Ministerio de Comunicaciones, en coordinación con UNICEF ${ }^{18}$.

Por su parte, en el año 1987 el Departamento Nacional de Planeación efectuó un diagnóstico de la Comunicación Social en Colombia, que tenía como objetivo principal dar prioridad a la infancia en los planes del Estado y, en general, de la sociedad colombiana. En el año 1989, mediante la ley 72 , se creó la Dirección Nacional de Comunicación Social, que buscaba fundamentalmente un desarrollo social en este campo y una presencia del Estado en los medios de comunicación. Estos estudios se enfocaron, principalmente, a la protección de la niñez y en

\footnotetext{
${ }^{15}$ Segura, Nora. "Usos sociales de la televisión y de la telenovela. La familia frente a la televisión: hábitos y rutinas de consumo en Cali", en J. Martín-Barbero, 5. Muñoz (coordinadores) Televisión y Melodrama, Bogotá, Tercer Mundo Editores, 1992. También ver: Segura, Nora. La familia frente a la televisión, Cali. Universidad del Valle, 1991.

${ }^{16}$ Yarce Maya, Jorge. "La televisión y la familia" en Arco (Bogotá), No. 239, diciembre, 1980; Que hacer con la televisión: Problemas y soluciones. Bogotá, Planeta, 1997.

${ }^{17}$ Rincón, Omar. Televisión, video y subjetividad. Bogotá. Norma. 2002.

${ }^{18}$ Programas y proyectos realizados en Colombia para la infancia y la adolescencia en los últimos veinte años, Bogotá, Instituto Colombiano de Bienestar Familiar (ICBF), Proyecto Comunicación para la Infancia, 2000 (policopiado).
} 
algunos casos de la madre como sostén de la familia nuclear tradicional. En este contexto se generó uno de los trabajos más importantes, provenientes del Estado, denominado Sistema de Seguimiento y Vigilancia de los Derechos de la niñez, entendiéndola como la etapa de la vida más vulnerable a los efectos de la televisión, llevado a cabo por la Defensoría del Pueblo, con el apoyo de UNICEF y la Fundación FES.

En la década de los 90, se inició el programa Supervivir (UNICEF) con los siguientes proyectos: a) Hogares comunitarios; b) Escuela Nueva; c) Programa de Universalización de la educación primaria en las áreas rurales. En esta misma dirección, la unidad de Medios Ciudadanos de la Dirección General de Comunicaciones del Ministerio de Cultura, creó las Mesas Regionales de Comunicación Ciudadana, con el propósito de generar espacios de comunicación entre los estamentos oficiales y la comunidad, en temáticas como la participación democrática y la formación ciudadana.

Igualmente, la Comisión Nacional de Televisión, con el Convenio Andrés Bello y la Fundación Restrepo Barco, desarrollaron un trabajo centrado en cómo promover el estudio de la relación educación-televisión en el país, con el fin de aportar elementos para la construcción de políticas locales, regionales y nacionales, en el ámbito de la comunicación y la televisión, dando como resultado la serie Televisión y Educación, que recoge documentos de eventos internacionales, nacionales y regionales, realizados por las instancias en mención, durante la década de los 90.

Las anteriores aproximaciones investigativas, dan cuenta del carácter polisémico en torno a la investigación sobre familia y televisión durante las últimas décadas, mostrando como han incursionado nuevas formas para entender la relación que se teje entre TV y formación de los sujetos, atendiendo a las multiplicidad de lecturas (apropiaciones críticas) que se pueden dar sobre el mensaje de la TV dependiendo del lugar socio cultural en el que se inscriban las cwnunidades de apropiación. No obstante, siguiendo a Martín-Barbero y Rey, digamos que las investigaciones en nuestro país sobre el tema de la comunicación revelan aún una fuerte paradoja:

Mientras existe un indudable encuentro de las propuestas epistemológicas y los debates metodológicos que se experimentan en las ciencias sociales con los que se plantean y trabajan en el campo de comunicación [...] en el terreno de los problemas y las demandas sociales el desencuentro es grande. Desde las ciencias sociales se desconoce la importancia política y cultural de los procesos y medios de comunicación, mientras en el espacio académico de los estudios de comunicación hay un generalizado desconocimiento del espesor social y político de la comunicación. La reticencia de la investigación social [...] a valorar como problemas dignos de investigación lo que pasa en los medios, pues allí sólo habría una 'subcultura' del entretenimiento, se verá complementada por la miopía de los estudios del campo acerca de la relación de los medios con los 
conflictos sociales de este país y con la incomunicación política que los medios catalizan ${ }^{19}$.

Para concluir esta parte digamos que las principales perspectivas teóricas del análisis sobre la relación existente entre comunicación-educación y, particularmente, en torno a la televisión, nos permite evidenciar tres grandes vías: una primera que podemos denominar 'apocalíptica', según la cual la TV incide negativamente en la formación de los sujetos por cuanto promueve valores nocivos para la vida en sociedad; la segunda, relacionada con una visión 'apologética', en la que se sobrevaloran las potencialidades formativas de la TV en la constitución de nuevos sujetos sociales; y, por último, una tercera perspectiva, en donde hay variados matices, que otorga tanto al medio como a las audiencias diversas posibilidades de relacionar-se; aquí podemos mencionar la forma en que las diferentes comunidades de apropiación realizan lecturas oblicuas de los códigos con los cuales se elaboran los distintos programas. A continuación aludiremos a las especificidades de la relación televisión-educación en las apreciaciones de algunas familias de la localidad Barrios Unidos.

\section{La TV como dispositivo pedagógico y como dispositivo político normativo}

En lo concerniente a la función educativa otorgada a la televisión, al igual que en la investigación de Leoncio Barrios en Venezuela mencionada en la primera parte, evidenciamos un reiterativo llamado de buena parte de las familias entrevistadas a que la programación nacional tenga un mayor componente formativo.

Consideramos que esta exigencia de una TV más formativa, antes que sugerir una reactivación del formato de la televisión educativa que conocimos hace algunos años, se dirige, por un lado, a que los diversos programas apoyen el desarrollo cognitivo y el rendimiento escolar de los niños y jóvenes - la TV como dispositivo pedagógico-, y, por otro lado, a que la televisión encauce la formación moral y ética de dichos actores, esto es, que la televisión contribuya al fortalecimiento de la formación ciudadana de los sujetos - la TV como dispositivo político normativo-. Veamos algunas particularidades de esta doble dimensión de la TV teniendo como referencia la información obtenida en el trabajo de campo en la localidad 12.

En cuanto a la TV como dispositivo pedagógico, se observó que la mayoría de las familias entrevistadas no ve una relación directa entre TV y escuela. Este dato podría ser interpretado, por lo menos de dos maneras. En primer lugar, es posible inferir que, efectivamente, hay un distanciamiento de las prácticas escolares y las

\footnotetext{
${ }^{19}$ Martln-Barbero, Jesñs y Rey, Germán. "La formación del campo de estudios de Comunicación en Colombia", en F Leal y G. Rey (editores), Discurso y Razón. Una historia de las ciencias sociales en Colombia, Bogotá, Ediciones Uniandes, Fundación Social, Tercer Mundo Editores, 2000, p. 257.
} 
prácticas televisivas reflejado en el poco uso de la televisión en el escenario educativo, es decir, que la TV en la escuela no es utilizada con regularidad para dinamizar los procesos de enseñanza-aprendizaje. En segundo lugar, podríamos considerar que los padres de familia no ven en la TV un elemento que pueda apoyar la realización de trabajos extraescolares de los niños y jóvenes. En relación con las entrevistas que apuntaron al sentido pedagógico de la televisión, pudimos encontrar que este sentido se relaciona con la inclusión de programas semejantes a los emitidos por canales internacionales como Discovery Channel, Animal Planet, History y National Geographic. Observemos las respuestas de la familia Gómez Benavides relacionadas con este aspecto:

E: ¿ Para ustedes la TV educa? F: En mi caso sí, en mi caso yo busco programas de ese tipo, yo rara vez veo televisión, como una película no. De hecho cuando yo prendo la televisión busco el canal 15 que es Discovery Channel, si no History Channel sino programas de tipo económico, o cuando hay una situación mundial que de pronto me interesa conocer más a fondo por eieniplo cuando la guerra con Irak, entonces me gusta ver canales así, que traten el tema con más profundidad. Nosotros no canalizamos el televisor para la niña como herramienta de aprendizaje sino más bien la canalizamos hacia los libros y hacia el internet, en el caso de ella la dejamos en libertad de que sea mas para su entretención pero controlándole la cantidad de tiempo que lo usa. Nosotros no vemos el televisor como la principal herramienta de aprendizaje. En mi caso porque veo esos canales, si no existieran esos canales ni siquiera me acercaría al televisor. E: ¿Ustedes creen que nuestra televisión sirve como factor educativo para la familia? F: Para la familia sí, pero para la educación está muy mal, por ejemplo antes pasaban documentales de diferente índole, sobre dinosaurios, me gustaban mucho, pero ya no pasan casi documentales, no pasan series buenas. Sería bueno que pasaran documentales como de historia y de desarrollo [sic]

Paralelo a esta solicitud de una programación más cercana a canales extranjeros como los mencionados en la cita, se evidencia que el concepto de educación está asimilado al de cultura, es decir, dentro de los habitantes de la localidad 12 entrevistados se asume que a mayor cultura, mayor educación. En este sentido, se considera que la televisión debe contribuir a aumentar los niveles culturales de la población.

Que le metieran más programas de cultura general, eso le sirve mucho al estudiante tanto universitario, secundario como de primaria para mejorar su calidad para enseñarle a más personas. La televisión se dedica únicamente a novelas yo creo que las novelas son muy fundamentales porque como tal distraen a la familia, tienen libretos muy buenos, pero también deberían existir programas de cultura general que le sirvieran al joven de hoy, al

\footnotetext{
*En la alusión a las entrevistas se encuentra la letra $E$, haciendo referencia al entrevistador, y la letra F, la cual muestra las respuestas de las familias. Así mismo, es necesario aclarar que algunos errores obedecen a que respetamos el formato dc trascripción de las entrevistas.
} 
estudiante que se está formando, para que enriquezca su léxico y para muchas $\operatorname{cosas}^{20}$.

El otro componente de la televisión como dispositivo educativo hace relación al acompañamiento y apoyo que presta la TV en la realización de los trabajos escolares. Buena parte de los entrevistados manifestó la necesidad que los programas televisivos pensaran más en las audiencias infantiles, particularmente, en las actividades académicas de los niños ${ }^{21}$. En esta parte es conveniente aclarar que dicha solicitud era más frecuente en las familias de ingresos económicos más bajos, pues en los hogares con mayor capacidad económica los niños y jóvenes pueden acceder a múltiples bienes culturales.

Frente a situaciones como la anteriormente descrita, algunos autores plantearían la necesidad de fortalecer la capacidad de lectura crítica de los medios en las audiencias escolares y familiares. Para Pérez Tornero, la sobrevaloración de la TV en la formación de los sujetos ha conducido a una suerte de sacralización y mistificación de dicho medio, frente a lo cual es indispensable generar competencias televisivas en los sujetos con el fin de facilitar la decodificación crítica del mensaje de los mismos. Estas competencias televisivas se relacionan, fundamentalmente, con tres aspectos: componente tecnológico, lingüístico y discursivo. En palabras de este autor:

A la ocupación televisiva del espacio privado sólo se puede responder con una estrategia de evasión frente al medio. Hay que procurar espacios que no puedan ser penetrados por la televisión, que resistan a ella. Se trata de interponer -en el tiempo y en el espacio- otros procesos de comunicación como la conversación, la escritura, la lectura... En fin. Todos aquellos modos que vendrían a procurar una elusión real de la, frecuentemente, abusiva presencia del mensaje televisivo ${ }^{22}$.

Este comentario de Pérez Tornero pareciera invitar a la negación de la televisión en cuanto artefacto cultural. No obstante, una mirada más detenida de su texto nos muestra que hace énfasis en la importancia de consolidar lecturas críticas del mensaje televisivo y, así, aprovechar su sentido de la mejor manera posible. La lectura crítica sería "aquella que busca aprovechar la propuesta de sentido de la televisión como una oportunidad para la recreación, para la reinterpretación, para el juego inteligente de sentidos"23. Esta lectura crítica, en palabras de Guillermo Orozco, hace referencia a la potencialidad pedagógica de la televisión y, a su vez, a la capacidad de las audiencias para "deconstruir" el mensaje de los medios y adecuarlo a sus necesidades culturales y educativas.

\footnotetext{
${ }^{20}$ Entrevista familia Flórez Restrepo (estrato 3). Barrio La Libertad, Bogotá, noviembre de 2003.

${ }^{21}$ Tal es el caso de la familia Hernández Galindo en donde generalmente se acude al televisor para resolver algunas tareas escolares.

22 Pérez Tornero, José Manuel. El desafío educativo de la televisión, Barcelona, Paidós, 1994, p. 143.

23 Ibid.. p. 148
} 
No se trata de hacer nuevas producciones televisivas, sino de hacer llegar a las audiencias las estrategias y los recursos para aprender conscientemente de la programación comercial de su preferencia [...] una deconstrucción televisiva desde las instituciones educativas y culturales debería aportar a los sujetosaudiencia, criterios, no para apagar el televisor o 'sacarle la vuelta', sino para ser más selectivos en sus televidencias y para explorarlas y explorarse a través de ellas ${ }^{24}$.

Cabe anotar que dentro de la propuesta de Orozco resultan de singular importancia los con-textos en los que tiene lugar la recepción televisiva, a la cual le otorga un carácter activo. Recordemos que en la perspectiva de la recepción activa se entendió que el proceso de recepción está mediado por un conjunto de influencias propias tanto de la mente del individuo como del contexto cultural en el que éste se encuentra. Asimilando la recepción al proceso de aprendizaje, se podrían identificar diferentes mediaciones de índole cognitiva (racionales y emocionales), situacionales (circunstancias en que ocurre la recepción), institucionales (esquemas transmitidos por las instituciones en que se ha desarrollado el individuo), estructurales (clase, género, etc.) e identitarias y culturales.

En lo concerniente a la TV como dispositivo político normativo es importante mencionar que durante la última década se ha fortalecido la tendencia a pensar que la formación de ciudadanos desborda el ámbito escolar y familiar. En relación con el papel de los medios de comunicación algunos autores han propuesto que el uso de los mismos puede estar dando origen a otra forma de ciudadanía, cual es la "ciudadanía mediática" ${ }^{25}$, en donde el principal espacio de socialización polftica es el medio de comunicación. Tomando en cuenta esta alusión, podemos ver que la gran mayoría de los habitantes de la localidad 12 entrevistados, principalmente los adultos, esperan que la televisión brinde una formación moral y ética basada en el respeto, la tolerancia, la solidaridad, entre otros valores. Algunos comentarios al respecto son los siguientes:

E: ¿Ustedes en la televisión notan algún elemento que les aporte al aspecto educativo tanto de la familia conw a los miembros de la familia? F: Ser más paciente, hay cosas que sí, la tolerancia, ser más pasivo. E: ¿Nos podría decir en que programa Usted nota esa característica? F: En el gran hermano, nos enseña a ser más paciente a tolerar. (Entrevista al niño): E: ¿Por qué no te gusta la televisión? F: Porque no hay noticias. E: Las noticias te dan miedo? F: Sí, porque hay muchos muertos. E: ¿Qué no te gusta de las noticias? F: La policia ${ }^{26}$.

\footnotetext{
${ }^{24}$ Orozco, Guillermo. Televisión. audiencias y educación, Bogotá, Norma, 2001, p. 103. mas transmitidos por las instituciones en que se ha desarrollado el individuo), estructurales (clase, género, etc.) e identitarias y culturales.

${ }^{25}$ Winocur, Rosalía. Ciudadanos medidticos: la construcción de lo público en la radio, Madrid, Gedisa, 2002.

${ }^{26}$ Entrevista a la familia Mora (estrato 3). Barrio Benjamín Herrera, octubre de 2003.
} 
Dentro de las apreciaciones anteriores se puede evidenciar una marcada preocupación por la presencia de imágenes televisivas que promueven la violencia. En el concepto de algunos adultos aún se considera que hay una relación de causalidad entre los índices de violencia en la televisión y las actitudes de agresividad en los niños. Las siguientes apreciaciones de la familia Trujillo Toscano se orientan en dicha dirección:

Hay programas educativos que le gusta ver, ero otros que no nos gusta que vea el Chayo, por ejemplo, nosotros de grandes nos hace reír todavía, pero muchas veces lo que no nos gusta es que el chino comienza a repetir todo lo que hacen en el Chavo, entonces uno le dice no se porte así que usted no es un bobo no es un tonto, él todo lo que ve en la televisión es a repetirlo. De igual forma esta haciendo otra cosa que no sea ver televisión y es como cantando las propagandas que ya las tiene regrabadas. Hay programas que a uno no le gustan y le dice no vea ese programa, los muñe quitos por decir algo, que a uno le parecen muy bonitos le parecen chéveres yo me divierto viendo los Simpson, pero me parece un programa muy pesado y pasado para un sardino, porque los niños siempre, y a él le pasa, es a repetir todo lo que le pasa a Bart Simpson, y como él tiene otra cosa que son pícaras, pesadas, entonces son las cosas que uno le dice a Yenco, no vea más ese programa ${ }^{27}$.

Consideramos que es necesario profundizar en la reflexión sobre las articulaciones que hay entre violencia y televisión entendiendo que los niños y jóvenes, además de tener contacto con las imágenes mediáticas de ja violencia, se socializan, en su mayoría, en espacios de conflicto. No obstante, es conveniente tener en cuenta que temas como la violencia y la democracia fueron claves, en la década del 80, para ampliar el campo investigativo sobre ja televisión. En este sentido, basta con recordar los proyectos Televisión y violencia, patrocinado por Colciencias en 1988 y el trabajo de Fernán González (Colombia: conflicto social y violencia) desarrollado en 1989, "donde se visualizará de manera más integral y fecunda el papel de los medios en la configuración de las violencias que vive el país"28.

Los estudios sobre televisión y violencia abrieron un campo analítico de gran interés en I momento actual, en el cual se han encontrado algunos estudios dirigidos a las articulaciones que tienen lugar entre política y medios de comunicación. Para Jesús Martín-Barbero ${ }^{29}$, hoy es posible evidenciar la existencia de una video política, en tanto los políticos han acudido al escenario mediático para la promoción de sus campañas. Sin profundizar en este aspecto, digamos que lo interesante de la reflexión radica en la sugerencia de tener en cuenta la multiplicidad de lugares desde los cuales se produce la realidad social y,

\footnotetext{
${ }^{27}$ Entrevista a la familia Trujillo Toscano (estrato 3). Barrio Aurora Norte, octubre de 2003.

28 Martín-Barbero, J. y Rey, G "La formación del campo de estudios de Comunicación en Colombia”, op. citp. 249.

${ }^{29}$ Martín-Barbero, Jesús. "Política y Comunicación. Desfiguraciones de la política y nuevas figuras de lo público”, en evista Foro, N' 45, Bogotá, septiembre de 2002.
} 
considerar, que la televisión sólo es uno de tales lugares. Así mismo, como lo sugirió David Morley, un análisis sobre la construcción de sentidos de la realidad a partir de la televisión debe tener en cuenta no tanto las actitudes de la gente, sino los marcos interpretativos desde los cuales construyen los fragmentos de realidad $^{30}$.

En esta parte, es importante mencionar que la televisión ha entrado a jugar un papel importante en la reconfiguración de las relaciones de poder que median la vida cotidiana de las familias. Contrario a otras tecnologías domésticas, la televisión ha facilitado el control de los niños sobre el uso de la misma y ha supeditado la voz de los adultos a las decisiones de la infancia. Así, la televisión ha reconfigurado no sólo la experiencia socio-cultural de los actores familiares, sino también la organización social del hogar y la manera en que se concibe y distribuye tiempo de las distintas actividades y roles de los actores familiares. No obstante, como lo sugirieron las investigaciones realizadas en España por el grupo de M. García y J. Callejo de la UNED, en algunas familias la televisión continúa funcionando como un factor de premios y castigos: si los niños cumplen con sus actividades académicas pueden acceder a ja TV, en caso contrario ésta permanece fuera de su alcance.

En síntesis, siguiendo las reflexiones de G. Orozco, la televisión, entendida como lugar de mediaciones, ha reconfigurado tanto las tradicionales 'urdimbres' de socialización en las cuales tenía lugar la experiencia de los actores familiares, como las construcciones - cognitivas, políticas, culturales- de los sujetos. Este proceso ha dado lugar al surgimiento de una relación conflictiva entre familia, televisión y educación, ya que, a pesar de la fuerte influencia de la TV la familia pareciera seguirse resistiendo al embate de los mensajes mediáticos, al igual que otros escenarios de socialización como la iglesia, los partidos políticos, las distintas expresiones de los nuevos movimientos sociales, entre otros. Sobre la importancia de la TV en la reconfiguración de las 'subculturas' modernas, Guillermo Orozco sugiere lo siguiente:

La televisión, ciertamente, inaugura una era donde la imagen y la tecnología videoelectrófica se autoinstituyen en significantes, no sólo en potenciales fuentes de significados, como sería el caso de la escuela y el libro [...] En la televisión, la imagen es al mismo tiempo significante y significado, por su concreción y por la universalidad que ha alcanzado el código visual. Pero lo es también porque lo audiovisual, a diferencia del texto escrito, automática y directamente se conecta con los sentidos de sus interlocutores (vista y oído) y luego se conecta con la razón (y a veces no), como sucede frecuentemente con las televidencias despreocupadas, fundamentalmente sensoriales $y$ emocionales de las audiencias ${ }^{31}$.

\footnotetext{
${ }^{30}$ Morley, David. Televisión, audiencias y estudios culturales, op. cit.

${ }^{31}$ Orozco, Guillermo. Televisión, audiencias y educación, op cit, p. 65-66. 
Cercano a estos planteamientos de Orozco, Martín-Barbero rescata el escenario familiar como uno de los tres lugares más significativos de mediación, junto a la temporalidad social y a la competencia cultural. Para este autor, en la familia hay dos dispositivos claves para entender la interpelación que se hace desde el hogar con respecto a la TV. Estos dos dispositivos son: la simulación del contacto y la retórica de lo directo. El primero hace referencia a los mecanismos mediante los cuales la televisión especifica su particular modo de comunicar (mantenimiento del contacto). El segundo dispositivo es el que organiza el espacio de la televisión sobre el eje de la proximidad y la magia del ver ${ }^{32}$.

En correspondencia con estas apreciaciones, el análisis de las entrevistas permitió evidenciar que a pesar de que buena parte de las familias aún otorgan algo de 'satánico', de 'perverso', a la televisión, continúan considerando a la misma como parte fundamental de las relaciones de socialización y de los procesos formativos de los sujetos. De allí que algunos de los entrevistados expresen una suerte de angustia para que la televisión aumente su capacidad formativa, con el fin de seguirla considerando como 'un integrante más de la familia'. No obstante, como anota Orozco, quizás el énfasis no habría que hacerlo en la televisión sino en la pedagogía televisiva de la familia para relacionarse con el medio.

Digamos, finalmente, que las intencionalidades educativas atribuidas, o exigidas, a la televisión han ocasionado una reconceptualización de la misma. De ser considerada, eminentemente, como un medio de dominación ideológica, para luego entrar en los análisis relacionados con las industrias culturales, hoy la reflexión sobre la televisión adquiere un carácter más amplio a partir del cual se reconoce una relación dialéctica entre el medio y los usuarios. El reconocimiento de esta relación permite ver en un sentido activo a las audiencias familiares, es decir, que las lecturas oblicuas que los actores familiares hacen del mensaje de la TV les convierten en coautores del mismo. Siguiendo las apreciaciones de MartínBarbero podemos anotar que:

En el caso de la TV la falta de un entorno ritual, su ubicación en el ámbito de lo familiar-cotidiano, refuerza esa situación y actitud de no recelo, de 'simpatía'. Puesto que forma parte de la familia, la pantalla encendida pierde todo carácter de agresor y se convierte en la gran compañera, ésa de cuya fidelidad es de las pocas que puede estar uno seguro hoy. La 'invasión' que la pequeña pantalla produce, la dominación que impone, son sentidas como liberación por el teleespectador habitual ${ }^{33}$.

El ingreso de la TV al universo de lo educativo ha mostrado la necesidad de fortalecer la reflexión sobre las relaciones de este medio con la escuela, pues, como anota María Teresa Quiroz, "un uso pedagógico creativo crítico de los medios y las nuevas tecnologías puede aportar la posibilidad de aprender de los

\footnotetext{
${ }^{32}$ Martín-Barbero, J. De los medios a las mediaciones, op.cit.

${ }^{33}$ Martin-Barbero, Jesús. Oficio de cartógrafo. Travesías latinoamericanas de la comunicación en la cultura, México, Fondo de Cultura Económica, 2002, p. 101.
} 
medios en lugar de aprender por los medios; apropiarse críticamente de sus contenidos y descifrar los cambios" ${ }^{34}$. Esta capacidad de 'desciframiento' de los códigos culturales implica, ante todo, que tanto la escuela como ha familia se separen del modelo "transmisivo" de valores y claves para entender la realidad desde el 'mundo adulto' y reconozca los múltiples recorridos culturales en que se forman las nuevas generaciones.

\section{Conclusiones}

El análisis de las entrevistas realizadas a varias familias de la localidad 12, permite inferir que hay una creciente demanda por más televisión educativa, esto es, que en lo posible los contenidos y la calidad de los espacios de las diferentes programadoras se orienten a fortalecer los procesos formativos de los actores familiares, principalmente de los niños y los jóvenes, en tanto que ellos son los mayores consumidores de televisión. No se trata, en ningún sentido, de volver a la propuesta de la televisión educativa de los años 70 , sino más bien de promover que la televisión, a través de programas de distintos géneros y de buena calidad, aporte elementos a la formación moral, cultural y cognitiva de los sujetos.

Otro de los cambios coagenciados por la televisión es la reestructuración, o por lo menos el cuestionamiento, de las relaciones de poder en el hogar. En esta perspectiva, fueron varios los casos de las familias en las que a la hora de ver televisión quienes tomaban las decisiones sobre el manejo del aparato eran los niños y no los adultos, entendidos como los que tradicionalmente toman las decisiones que afectan la cotidianidad del hogar. Podemos sugerir que el uso de la televisión, entendida como un integrante más del hogar, ha generado una dislocación de las relaciones de autoridad que sostenían a las familias tradicionales dando paso a unas relaciones más flexibles y a un reconocimiento de los niños como sujetos activos en la vida del hogar.

En lo que tiene que ver con el campo teórico, el desarrollo de esta investigación nos puso frente a la necesidad de fortalecer otro lugar desde el cual mirar y analizar la familia: la comunicación. De todos es sabido que la familia ha sido, históricamente, objeto de investigación, principalmente, de disciplinas como la sociología (la cual la mira en tanto espacio de socialización), la antropología (que la asume como un escenario de producción simbólica y cultural) y la psicología (en la cual la familia es la encargada de la construcción de la personalidad moral de la sociedad). De acuerdo con el horizonte de las mediaciones culturales, consideramos oportuno introducir la idea de pensar la familia desde la comunicación, es decir, asumir ésta como un espacio social cuyas dinámicas y reconfiguraciones puedan ser comprendidas a partir de las diversas estrategias y ritmos de la comunicación.

\footnotetext{
${ }^{34}$ Quiroz, María Teresa. Aprendizaje y comunicación en el siglo XXI, Bogotá, Norma, 2003, p. 70. 
Para terminar, subrayemos la importancia de que la academia y las organizaciones gubernamentales se detengan en la reflexión y construcción de una agenda televisiva que permita cualificar, no sólo los contenidos de la misma, sino también democratizar las formas de control sobre los medios de comunicación. Estas estrategias se constituyen en una forma de medir la democratización de nuestra sociedad, entendiendo que "en la gran mayoría de familias colombianas, donde las ofertas de canales de televisión y de emisoras de radio superan con creces los periódicos o impresos que reciben, o las oportunidades de lectura o información, quizás sean los sistemas de radio y TV unos de los pocos bienes culturales disponibles para pensar y decidir sobre sus propias vidas"35. En última instancia, pensar las relaciones entre televisión, educación y familia, es reflexionar sobre una parte significativa del tipo de sociedad que deseamos construir en los próximos años.

\section{BILIOGRAFÍA}

AGUADED, José. (1999) Convivir con la televisión. Familia, educación y recepción televisiva. Buenos Aires: Paidós.

ALFARO, Rosa María; MACASSI, Sandro. (1995) Seducidos por la Tele. Huellas educativas de la televisión en padres y niños. Lima: Clandria.

AAVV. (2003) Programas y proyectos realizados en Colombia para la infancia y la adolescencia en los últimos veinte años. Bogotá: Instituto Colombiano de Bienestar Familiar (ICBF), Proyecto Comunicación para la Infancia (policopiado).

BARRIOS, Leoncio. (1992) Familia y televisión. Caracas: Monte Avila Editores.

CHARLES, Mercedes; OROZCO, Guillermo. (1990). Educación para la recepción. Lectura crítica de medios. México: Trillas.

FUENZALIDA, Valerio. (1984) Televisión, padres e hijos. Santiago de Chile: Ediciones Paulinas.

GARCÍA, María Luisa; CALLEJO GALLEGO, Javier; DEL VAL CID, Consuelo; CAMARERO RIOJA, Luis; ARRANZ LOZANO, Fátima. (1994) La influencia de la familia y los educadores en la percepción y asunción de los mandatos sobre la televisión. Barcelona: Centro Nacional de Investigación y Documentación Educativo, Ministerio de Educación y Ciencia.

HUERGO, Jorge Alberto; HERNÁNDEZ, María Belén. (1999) Cultura Escolar, Cultura mediática / Intersecciones. Bogotá: Universidad Pedagógica Nacional.

\footnotetext{
${ }^{35}$ López de la Roche, Maritza; Martín-Barbero, Jesús; Rueda, Amanda y Valencia Stella, Los Niños como audiencias, op. cit. p. 394.
} 
LÓPEZ DE LA ROCHE, Maritza. (2000) Los Niños como audiencias. Investigación sobre recepción de medios. Bogotá: Instituto Colombiano de Bienestar Familiar, Proyecto Comunicación para la infancia.

MARTíN-BARBERO, Jesús. (1987) De los medios a las mediaciones. Comunicación, cultura y hegemonía. Barcelona, Gustavo Gili.

MARTíN-BARBERO, Jesús; REY, Germán. (2000) La formación del campo de estudios de Comunicación en Colombia", en F. Leal y G. Rey (editores), Discurso y Razón. Una historia de las ciencias sociales en Colombia. Bogotá: Ediciones Uniandes, Fundación Social, Tercer Mundo Editores.

MARTíN-BARBERO, Jesús. (Septiembre de 2002) Política y Comunicación. Desfiguraciones de la política y nuevas figuras de lo público, en Revista Foro, $\mathrm{N}^{0}$ 45, Bogotá.

MARTíN-BARBERO, Jesús. (2002) Oficio de cartógrafo. Travesías latinoamericanas de la comunicación en la cultura. México: Fondo de Cultura Económica.

MORLEY, David. (1996) Televisión, audiencias y estudios culturales. Buenos Aires: Amorrortu Editores.

OROZCO, Guillermo. (2001) Televisión, audiencias y educación. Bogotá: Norma.

PÉREZ TORNERO, José Manuel. (1994) El desafío educativo de la televisión. Barcelona: Paidós.

QUIROZ, María Teresa. (1993) Todas las voces. Comunicación y educación en el. Perú. Lima: Universidad de Lima.

QUIROZ, María Teresa. (2003) Aprendizaje y comunicación en el siglo XXI. Bogotá: Norma.

RINCÓN, Omar. (2002) Televisión, video y subjetividad. Bogotá: Norma.

SEGURA, Nora. (1991) La familia frente a la televisión. Cali: Universidad del Valle.

SEGURA, Nora. (1992) Usos sociales de la televisión y de la telenovela. La familia frente a la televisión: hábitos y rutinas de consumo en Cali", en J. Martín-Barbero, 5. Muñoz (coordinadores) Televisión y Melodrama. Bogotá: Tercer Mundo Editores.

SILVERSTONE, Roger. (1996) Televisión y vida cotidiana. Buenos Aires: Amorrortu. 
WINOCUR, Rosalía. (2002) Ciudadanos mediáticos: la construcción de lo público en la radio. Madrid: Gedisa.

YARCE MAYA, Jorge. (Diciembre de 1980) La televisión y la familia, en Arco. Bogotá, No. 239.

YARCE MAYA, Jorge. (1997) Que hacer con la televisión: Problemas y soluciones. Bogotá: Planeta. 